\title{
A PASSAGEM AO ATO NA NEUROSE E NA PSICOSE
}

\section{The Passage to the Act in Neurosis and Psychosis}

\author{
El Pasaje al Acto en la Neurosis y en la Psicosis
}

Artigo Original

\section{Le Passage à L'acte dans la Névrose et dans la Psychose}

\begin{abstract}
Resumo
A partir de um caso clínico acompanhado pelo Programa de Atenção Integral ao Paciente Judiciário - PAIPJ, do Tribunal de Justiça de Minas Gerais (TJMG), este trabalho se propõe a indagar sobre a passagem ao ato na teoria psicanalítica e suas possíveis especificidades nas estruturas clínicas neurótica e psicótica. Para tanto, foram trabalhados os conceitos de passagem ao ato e acting out, tomando como referências principais os desenvolvimentos teóricos de Sigmund Freud e Jacques Lacan. O trabalho permitiu elucidar que a passagem ao ato na neurose é a precipitação do sujeito, a partir de um encontro desestabilizador, para fora da cena fantasmática onde ele ocupava uma posição de resposta ao desejo do Outro. Já na psicose, há uma tendência a operar diretamente sobre o real nos fenômenos de passagem ao ato, como forma de barrar o Outro em sua dimensão invasiva e excessiva. Discute-se, ainda, a partir do caso clínico, a relação que o sujeito psicótico pode estabelecer com seu corpo e como a falta de recursos diante de um gozo que não se localiza, pode, às vezes, levá-lo à morte.
\end{abstract}

Palavras-chave: psicanálise; passagem ao ato; acting-out; psicose; neurose.

\begin{abstract}
From a clinical case followed by the Program of Integral Attention to the Patient Judiciary PAIPJ from the Court of Minas Gerais, this paper inquires about the passage to the act in the psychoanalytic theory and its possible specificities of the neurotic and psychotic structure. Therefore, the concepts of passage to the act and acting out were worked having as main references the theoretical developments of Sigmund Freud and Jacques Lacan. This paper allows clarifying that the passage to the act in neurosis is the precipitation of the subject, from a destabilizing meeting, out of the fantasy scene in which he occupied a position in response to the desire of the other. In the psychosis there is a tendency to operate directly on the real in the occurrence of passage to the act, as a way of stopping the Other in his invasive and excessive dimension. By the presented clinical case, this article discussed the relation among anguish and act, in addiction how into the psychosis the anguish is borderless and how it doesn't work as a signal, to the subject can be easier commit a passage to the act. This paper discusses yet the relationship that the psychotic subject has with his body and how the lack of resources in front of the enjoyment without location can sometimes lead him to death.
\end{abstract}

Keywords: psychoanalysis; passage to the act; acting-out; psychosis; neuroses.

\section{Resumen}

A partir de un caso clínico acompañado por el Programa de Atención Integral al Paciente Judicial - PAIPJ - del Tribunal de Justicia de Minas Gerais, el presente trabajo indaga acerca del acto de la teoría psicoanalitica y sus posibles especificidades de las estructuras clínicas neurótica psicótica. Para ello se trabajó los conceptos del pasaje al acto y acting out con referencias principales de los desarrollos teóricos de Sigmund Freud y Jacques Lacan. El trabajo permitió elucidar que el pasaje al acto en la neurosis es la precipitación del sujeto a partir de un encuentro desestabilizador fuera de escena en la cual ocupó una posición de respuesta al deseo del Otro. Ya en la psicosis, hay una tendencia de operar directamente sobre lo real de los fenómenos de pasaje al acto como una manera de detener

\section{Gabriela Rodrigues Mansur de \\ Castro( $^{(1)}$ \\ Ângela Maria Resende Vorcaro ${ }^{(2)}$}

1) Psicóloga graduada e mestre em Psicologia pela Universidade Federal de Minas Gerais (2012). Psicóloga judicial do Tribunal de Justiça de Minas Gerais desde 2003.

2) Professora adjunta do departamento de psicologia UFMG. Graduada em psicologia pela PUC (MG), é mestre e doutora em Psicologia pela PUC (SP). É também membro do corpo editorial da revista Estilo da clínica (USP).
Recebido em: 04/02/2013 Revisado em: 11/11/2014 Aceito em: 11/11/2014 
el Otro en su dimensión invasiva y excesiva. A partir del caso presentado se discute, todavía, la relación del sujeto psicótico y su cuerpo y cómo la falta de recursos frente a un goce que no se localiza puede, por veces, llevarlo a la muerte.

Palabras clave: psicoanálisis; actuación; acting-out; psicosis; neurosis.

\section{Résumé}

A partir d'un cas clinique traité dans le Programme d'Attention Intégrale du Patient Judiciaire - PAIPJ, de la Cour de Justice de Minas Gerais, ce travail pose la question de la spécificité du passage à l'acte chez les sujets névrotiques et psychotiques. Pour cela, des points théoriques ont été élaborés à fin d'élucider les concepts de passage à l'acte et acting out, ayant comme références les dévellopements théoriques de Sigmund Freud et Jacques Lacan. Cette analyse a permis d'explicité que le passage à l'acte dans la névrose est la précipitation du sujet, dans le contexte d'une rencontre troublante, au dehors de la scène fantasmatique dans laquelle il occupait une position de répondre au désir de l'Autre. Dans la psychose, il y a une tendance à opérer directement sur le réel dans les phénomènes de passage à l'acte, comme tentative d'arrêter l'Autre dans sa dimension envahissante et excessive. Il a été également discuté, à partir du cas clinique, la relation que le sujet psychotique peut établir avec son corps, et comment le manque de ressources face à une jouissance qu'on ne puet pas situer a le pouvoir de, parfois, le conduire vers la mort.

Mots-clés: psychanalyse; passage à l'acte; acting out; névrose; psychose.

No trabalho clínico, deparamo-nos frequentemente com atuações ${ }^{1}$ de pacientes. Tal situação dificulta, gera impasses e, muitas vezes, cria um impedimento para o tratamento. Num serviço como o Programa de Atenção Integral ao Paciente Judiciário (PAIPJ) ${ }^{2}$, do Tribunal de Justiça de Minas Gerais, que realiza por meio de equipe interdisciplinar (psicólogos, assistentes sociais e assistentes jurídicos) o acompanhamento de pacientes com sofrimento mental que cometeram crimes, o tema das atuações é recorrente, afinal, é a partir um de ato considerado como crime pelo Código Penal Brasileiro, que o paciente passa a ser acompanhado pelo Programa.

A temática do ato envolve a clínica freudiana a partir da oposição entre recordação e atuação. Além disso, na história da psicanálise, os desenvolvimentos teóricos realizados por Jacques Lacan tiveram a importante função de estabelecer

\footnotetext{
1 Trataremos, indistintamente, nesta parte do texto, os conceitos de passagem ao ato (ato) e acting out (atuação). Posteriormente, apresentaremos uma conceitualização dos termos referidos

2 Para maiores informações sobre o Programa de Atenção Integral ao Paciente Judiciário (PAIPJ), ver: http:// www.tjmg.jus.br/ portal/acoes-e-programas/novos-rumos/pai-pj
}

uma diferença conceitual entre passagem ao ato e acting out. Tal diferenciação é fundamental por sua operatividade clínica, o que se verá a partir do caso clínico apresentado. Trata-se de um sujeito que cometeu um homicídio e que se apresentava através de inúmeras atuações: brigas, agressões, quedas, atropelamentos, entre outros. Esse caso nos levou a interrogar, em função de uma primeira dúvida quanto ao diagnóstico, se haveria uma especificidade no estatuto da passagem ao ato considerando a estrutura clínica. Nessa pesquisa, interessou-nos, particularmente, a neurose e a psicose. Outra pergunta que se apresentou em função das diversas e frequentes atuações da paciente foi se haveria uma linha divisória clara entre o acting out e a passagem ao ato. Assim, este trabalho se propõe a elucidar tais indagações a partir de uma articulação entre o caso clínico e a discussão teórica realizada. Durante a escrita do caso, outros pontos fundamentais se apresentaram, dos quais se ressalta a relação entre ato e angústia, ponto que também foi de interesse teórico na presente pesquisa.

\section{A Clínica de Freud e o Ato}

É na perspectiva do ato falho ou do ato sintomático que a temática do ato surge na psicanálise freudiana. Para Freud esses atos não são inocentes, não são meros movimentos, têm uma significação e são interpretáveis, do mesmo modo que um sonho o é. No entanto, em sua clínica, Freud irá se deparar com atuações de seus pacientes que o farão, a partir do texto Recordar, repetir e elaborar, de 1914, discutir os atos em oposição à rememoração.

Freud (1914/1996b) retoma os primórdios da história da psicanálise e da técnica da hipnose, que permitia ao paciente recordar, por meio da sugestão do médico, o momento em que o sintoma se formava, reproduzindo os processos mentais envolvidos nessa situação a fim de dirigir-lhes uma descarga (catarse) ao longo do caminho da atividade consciente. Assim, ocorria a recordação do momento traumático que produziu o sintoma e, em seguida, sua abreação. Contudo, com o abandono da hipnose, a tarefa era, a partir das associações livres do paciente, descobrir o que ele deixava de recordar e a resistência deveria ser contornada pelo trabalho da interpretação, ou seja, o analista revela as resistências que são desconhecidas ao paciente e quando vencidas por este, as lacunas da memória seriam então preenchidas.

Freud(1914/1996b) prossegue a discussão mencionando casos de pacientes que, ao serem convidados a associarem livremente, nada tinham a dizer, ou seja, apresentavam uma resistência contra o recordar. Ao não recordar, o paciente expressa o conteúdo esquecido e recalcado por meio de atuações (acts it out). "Ele o reproduz não como lembrança, mas ação, repete-o, sem, naturalmente, saber que o está 
repetindo" (p. 165).

Interessa a Freud a relação desta compulsão à repetição com a transferência e com a resistência, sendo a transferência um fragmento da repetição e a repetição uma transferência do passado esquecido, não apenas para a figura da analista, mas também para todos os outros aspectos da situação vivida no momento pelo paciente. Quanto à resistência, esclarece Freud (1914/1996b), quanto maior for, "mais extensivamente a atuação (acting-out) (repetição) substituirá o recordar, pois o recordar ideal do que foi esquecido, que ocorre na hipnose, corresponde a um estado no qual a resistência foi posta completamente de lado" (p. 166).

Em relação à transferência, Freud aponta ainda que se ela se mantém positiva e branda é possível desenterrar lembranças e manter os sintomas inativos durante o tempo do tratamento. Todavia, com o avanço do processo da análise, se a transferência se torna hostil ou excessivamente intensa, o recordar imediatamente abre caminho à atuação (acting out). Daí por diante, as resistências determinam a sequência do material que deve ser repetido. "O paciente retira do arsenal do passado as armas com que se defende contra o progresso do tratamento - armas que lhe temos que arrancar, uma por uma" (Freud, 1914/1996b, p. 167), pois ele repete (acts out) suas atitudes, inibições e todos seus demais sintomas sob as condições da resistência. Nestes casos, a tática a ser adotada pelo analista é a de manter na esfera psíquica todos os impulsos que o paciente gostaria de dirigir para a esfera motora, ou seja, que algo que o paciente deseja descarregar seja utilizado no trabalho de recordar. Tal empreendimento só se torna possível se a transferência é útil, ou seja, é o manejo da transferência que serve de principal instrumento para tratar a compulsão à repetição e transformá-la num motivo para que o paciente recorde, e a isso Freud nomeia de uma substituição da neurose comum por uma neurose de transferência, na qual o trabalho terapêutico pode então acontecer.

Sobre o trabalho de elaboração, Freud (1914/1996b) esclarece a importância de se dar tempo ao paciente para se familiarizar melhor com suas resistências - interpretadas pelo analista - a fim de superá-las. Para o pai da psicanálise, mesmo sendo uma tarefa árdua para o sujeito em análise e uma prova de paciência para o analista, o trabalho de elaboração das resistências é o que pode efetuar as maiores mudanças no paciente, além de ser o que de fato difere o tratamento analítico de qualquer tipo de tratamento por sugestão.

A partir dessas teorizações freudianas, indagamos: se a clínica privilegia o dizer/recordação, como lidar com o ato que parece não dar um lugar a esse tipo de dizer que está no cerne da prática analítica proposta por Freud? Esse é o desafio que a prática clínica coloca, como poderemos ver nos dois casos a seguir.

\section{O Caso Dora e o Caso da Jovem Homossexual}

Dora é uma jovem de 18 anos que vai se tratar com Freud, levada por seu pai. Ela apresentava tosse nervosa, afonia, enxaqueca, entre outros sintomas. A amizade de Dora e seu pai pelo casal "K" revela uma trama em suas relações. Quando Dora ainda era criança, seu pai adoece, é cuidado pela Sra. K. e acabam por se tornar amantes, embora ele fosse impotente. O Sr. K. mostra-se, então, muito amável em relação à jovem Dora. Além disso, Dora ocupase dos filhos dos K., numa posição maternal, e ao mesmo tempo mantém uma relação de afeição e admiração para com a Sra. K., havendo nesse quarteto uma cumplicidade mútua. Porém, durante um passeio no lago, o Sr. K. faz nova investida amorosa à Dora, afirmando que sua mulher nada significava para ele. Nesse momento, Dora the desfere uma bofetada e, a partir disso, passa a se sentir oferecida pelo pai àquele homem e exige que o pai rompa o relacionamento com os "K", mas como ele não atende ao seu pedido, ela faz uma ameaça de suicídio, quando então é levada a Freud.

Como o Sr. K. somente tinha valor para Dora porque desejava a Sra. K., dizer para ela que sua a esposa não era nada produz como efeito cortar de uma só vez a identificação histérica de Dora: identificação masculina na medida em que ela se identifica à posição do $\mathrm{Sr}$. K. ou à do pai no amor à Sra. K., e a identificação feminina na medida em que desejaria ser amada pelo Sr. K. e por seu pai, à maneira pela qual a Sra. K. é amada por seu pai. Dessa forma, no momento em que cai a identificação, Dora faz um ato ao desferir uma bofetada contra o Sr. K. Também se entende que ela atuava enquanto sustentava a cena da trama relacional entre seu pai e os " $\mathrm{K}$ ".

Cabe ainda mencionar que Dora abandona o tratamento que com iniciado com Freud. Lacan (2002) aponta que Freud viu seu erro, qual seja, o de não ter reconhecido o verdadeiro objeto de amor de Dora (a sra. K) ao insistir na ideia de que era a impossibilidade em que ela se encontrava de se desvincular do objeto principal de seu amor, seu pai, que a impedia de ir em direção a um objeto mais normal, ou seja, um outro homem. Ao insistir na identificação de Dora ao pai, Freud acaba provocando um rompimento prematuro que não permite a resolução do caso. Essa situação evidencia o quanto o manejo da transferência e as interpretações do analista podem favorecer ou não a superação de suas resistências e o trabalho de recordação do paciente, podendo inclusive gerar tal acirramento das resistências que o abandono do tratamento é o que se produz como consequência.

No caso da jovem homossexual, trata-se de uma moça que apresenta um comportamento homossexual 
enamorando-se de uma cocotte, sua dama. Segundo Freud, até os 16 anos de idade, essa moça apresentava um desenvolvimento normal do complexo edípico, todavia, quando nasce seu terceiro irmão, isso lhe traz uma decepção, visto que o bebê confirma a união dos pais levando-a a constatar que não é mais objeto de desejo do pai. Assim, ela se afasta de seu genitor, porém não muito, na medida em que o leva ao desespero com sua atitude homossexual em relação à dama.

Como consegue o consentimento da dama para passearem juntas, a jovem a leva para caminharem próximo ao escritório do pai, o que é interpretado como uma convocação ao olhar do genitor para a cena. No entanto, em um determinado dia acabam por serem vistas pelo pai da jovem, momento em que o genitor lança um olhar irado sobre a filha. A dama, que só então fica sabendo quem ele era, diz à jovem que nunca mais quer vê-la. Nesse instante, diante do olhar do pai e da reação da dama, a jovem se joga na linha ferroviária, pulando sobre o muro de proteção. Aqui se pode entender que a jovem cai da cena como puro objeto a partir do olhar do pai e da rejeição da dama. Ou seja, nesse caso, a impossibilidade de recordar e elaborar sobre a questão de seu lugar como filha no desejo pai, acaba por produzir uma passagem ao ato da paciente.

Para melhor esclarecer sobre a distinção entre passagem ao ato e acting out, retomaremos os aportes teóricos produzidos por Jacques Lacan em seu seminário sobre a angústia.

\section{Acting Out e Passagem ao Ato}

É sabido que, embora Freud não tenha feito uma distinção entre passagem ao ato e acting out, os casos "A psicogênese de um caso de homossexualismo numa mulher" (1920/1996c) e "Fragmento da análise de um caso de histeria" (1905 (1901) /1996a), ambos analisados por ele, são discutidos por Lacan em "O Seminário Livro 10: A angústia" (1962-63/2005) e se tornaram paradigmáticos na diferenciação dos conceitos supracitados.

Na lição de 23 de janeiro de 1963, intitulada Passagem ao ato e acting out: Deixar-se cair e subir no palco, Lacan retoma o caso da jovem homossexual e o momento de sua passagem ao ato. Recorda o termo usado por Freud: niederkommen lassen, traduzindo-o para o francês como laisser tomber (deixar cair), essa expressão como correlata à passagem ao ato.

O momento da passagem ao ato é o do embaraço maior do sujeito, com o acréscimo comportamental da emoção como distúrbio do movimento. É então que, do lugar em que, como sujeito fundamentalmente historizado, só ele pode manter-se em seu status de sujeito, ele se precipita e despenca fora da cena. Essa é a própria estrutura da passagem ao ato. (Lacan, 2005, p. 129)

$\mathrm{Na}$ tentativa de diferenciar a passagem ao ato do acting out, Lacan nos aponta uma distinção, que denomina de essencial, entre dois registros: de um lado o mundo, lugar do real; do outro lado, a cena do Outro, lugar onde o sujeito tem que se assumir como portador da fala.

Esclarece que tudo que é acting out é o oposto da passagem ao ato, logo, ao contrário da passagem ao ato, o acting out é um apelo ao Outro, e "essencialmente, alguma coisa que se mostra na conduta do sujeito. A ênfase demonstrativa de todo acting out, sua orientação para o Outro, deve ser destacada" (Lacan, 2005, p. 137).

No caso da jovem homossexual, ele nos aponta que sua tentativa de suicídio é uma passagem ao ato, enquanto a aventura com a dama que ela exibe aos olhos de todos é um acting out. Assim como a bofetada de Dora no Sr. K. é uma passagem ao ato e sua relação com os "k" é da ordem de um acting out.

Ainda no Seminário sobre a angústia, Lacan (2005) apresenta um quadro esquemático onde procura situar a partir da tríade freudiana inibição, sintoma e angústia, o acting out e a passagem ao ato.

No quadro esquemático, ele localiza no eixo horizontal a ideia de dificuldade e, no vertical, a ideia de movimento. Esclarece que o que está em jogo na inibição é a paralisação do movimento. Serve-se da palavra impedimento, colocando-a na mesma coluna do sintoma e, seguindo a coordenada da dificuldade, propõe o termo embaraço, que define como uma forma leve de angústia e o máximo da dificuldade atingida.

\begin{tabular}{|l|l|l|}
\multicolumn{3}{c}{ Dificuldade } \\
\cline { 2 - 4 } \\
\\
\hline Inibição & Impedimento & Embaraço \\
\hline Emoção & Sintoma & Passagem ao Ato \\
\hline Efusão & Acting-out & Angústia \\
\hline
\end{tabular}

Figura 1. Quadro esquemático: inibição, sintoma e angústia (Lacan, 2005, p. 22).

Na dimensão do movimento, logo abaixo da inibição, propõe o termo emoção, tomando-o em seu sentido etimológico como sendo o movimento que se descarrega, que se exterioriza. Em seguida vem a efusão, definida como queda da potência, uma perturbação profunda na dimensão do movimento.

Carvalho (2002) aponta dificuldades na interpretação do quadro lacaniano, levando em conta que Lacan não o retomou posteriormente ao seminário da angústia, esclarecendo ainda que é possível relacionar os termos se 
não os tomarmos como um todo. O quadro caminha de um mínimo a um máximo de movimento e de uma menor a uma maior dificuldade, "de forma que podemos definir a angústia como resultante de um máximo de movimento com um máximo de dificuldade" (p. 70).

Ao introduzir em um eixo diagonal a série freudiana inibição, sintoma e angústia, Lacan (2005) indica que não há relação de passagem ou gradação entre eles. Contudo, se a inibição está relacionada à detenção do movimento, ela se opõe à angústia, sendo o sintoma o que faz mediação entre movimento e dificuldade, ou seja, uma formação de compromisso entre o movimento pulsional e a defesa.

Observa-se que, no eixo da dificuldade, há maior proximidade entre sintoma e acting out, e entre passagem ao ato e angústia. $\mathrm{O}$ acting out pode se produzir a partir de um franqueamento do sintoma, onde se encontra um atravessamento do campo simbólico (do sintoma) por uma mostração direcionada ao Outro que encena a relação fantasmática entre sujeito e objeto. Já na passagem ao ato ocorre uma precipitação que lança o sujeito em um movimento para fora da cena (Carvalho, 2002).

Feito esse percurso, veremos como o acompanhamento de um caso realizado no Programa de Atenção Integral ao Paciente Judiciário (PAIPJ) nos levou a uma dúvida sobre o diagnóstico e, derivada desta, uma outra pergunta: a passagem ao ato se apresenta de forma distinta na neurose e na psicose? É esta questão, entre outras, que procuraremos elucidar.

\section{O Caso Clínico}

\section{Legítima Defesa}

O caso de Ana chegou ao Programa de Atenção Integral ao Paciente Judiciário - PAI-PJ por meio de Helena, uma antiga amiga da família. Ela conta que Ana, 27 anos de idade, havia sido presa em flagrante por ter quebrado um posto de saúde, ocasião em que destruiu mobiliários e computadores. Afirma ainda que a paciente sofria de epilepsia.

Em pesquisa jurídica, verificou-se que havia contra Ana um mandado de prisão em aberto, relativo ao homicídio de seu amásio. Constava que Ana havia matado o companheiro, José, envenenado. José faleceu e foi enterrado como se fosse vítima de morte natural, todavia, uma semana depois, Ana foi à delegacia e confessou o crime. Constava também o processo por dano ao patrimônio, relativo ao posto de saúde.

Em atendimento, indagada acerca do dano provocado com a quebra de mobiliário e inúmeros objetos do posto de saúde, Ana conta que a razão de tudo foi o fato de que seu primo estava muito mal, ela o estava acompanhando para uma consulta e houve demora no atendimento. Afirma que, assim como ela, sofria de epilepsia. Diante da demora, Ana foi solicitar urgência e a atendente lhe respondeu mal. Segundo ela, nesses momentos, suas vistas escurecem e não vê mais o que faz, foi então que passou a quebrar o posto. Como a polícia foi imediatamente acionada, Ana foi presa em flagrante. A situação foi capa da reportagem em um jornal sensacionalista. Chama atenção a foto de Ana algemada e um rastro de desordem e destruição em sua volta, onde se via um sem-número de prontuários médicos espalhados por todos os lados, computadores destruídos pelo chão, mobiliário quebrado, gavetas e portas de armários abertas.

Quanto ao homicídio do ex-companheiro, ela relata que colocou veneno em sua comida, pois "o que ele falava, fazia" (sic), e ele tinha dito que a mataria e aos filhos. Se o histórico de tratamento de Ana realizado na rede pública de saúde indicava que se tratava de um caso de epilepsia a ser tratado exclusivamente por medicações neurológicas, sua afirmação parece indicar uma certeza acerca do cometimento do ato por parte do companheiro. Conta que no mesmo dia em que ele a ameaçou, decidiu matá-lo e que não havia pensado nas consequências de tal ato. Questionada acerca da possibilidade de outra saída que não o envenenamento, Ana afirma que não havia, pois se se separasse de José e fosse viver com os filhos e outro homem, ele não permitiria. Diz que hoje se sente aliviada - significante que se repete toda vez que fala de sua relação com a consequência de seu ato: alívio -, pois se o companheiro estivesse vivo, ela estaria se prostituindo, como na época em que ele era vivo, e que seu ato fora "legítima defesa" (sic).

Em seus atendimentos com a equipe do PAIPJ, Ana demanda frequentemente saber onde estavam os filhos que teve com José, tendo em vista que, após a morte do companheiro, as crianças permaneceram sob os cuidados da tia paterna, todavia Ana não sabia onde estavam residindo. A partir das informações obtidas, confirmou-se que a tia paterna havia entrado com um processo para a adoção dos sobrinhos. Nesse processo, constava documentação do Conselho Tutelar contendo denúncias de maus-tratos e descuidos de Ana e de José em relação aos filhos.

Ana justifica muitas de suas atitudes, envolvendo, na maioria das vezes, agressões físicas, em função de suas "crises". Conta que foi ao médico e ele aumentou a dose de Gardenal/Fenobarbital e Fenitoína (medicações anticonvulsivantes usadas para tratar epilepsia) e, além disso, ele havia solicitado um exame neurológico, que não chegou a ser realizado. Ela ainda menciona que familiares seus morreram de epilepsia. Durante o atendimento, Ana afirma que faz uso das medicações citadas desde os 16 anos de idade. Esses sempre foram os medicamentos utilizados por ela em grande parte de seu tratamento na rede de saúde pública. Após um período, o psiquiatra que a acompanhou 
no centro de saúde afirmou que seu caso não era para a psiquiatria, mas para a neurologia, suspendendo então as consultas.

Tomando as cenas descritas por Ana, no caso da destruição do posto de saúde, identificada ao primo, também epiléptico, ela parece agir se endereçando ao Outro, pois há um apelo de cuidado e de atenção, o que nos levaria a conceber este ato na dimensão de um acting out, tendo em vista que a referida situação foi tomada como uma grave crise histérica de Ana. Contudo, o rastro de destruição a sua volta, leva-nos a sustentar que, em um momento inapreensível, ela se apresenta desgarra de qualquer relação com o Outro, permitindo-nos designar este acontecimento como uma passagem ao ato. Seu olhar assustado registrado pela foto estampada no jornal parece mostrar algo de uma perplexidade diante de uma cena na qual ela não consegue se localizar. Importante destacar nessa cena a confusão imaginária entre ela e primo.

Quanto ao envenenamento do companheiro, sua certeza de que ele a mataria e aos filhos e seu ato contínuo de envenená-lo, sua "legítima defesa", parece indicar que sua atuação se amarra a essa certeza. Sua impossibilidade de dialetizar seja o dizer do companheiro, seja sua decisão de matá-lo, aponta-nos para uma hipótese diagnóstica de psicose.

Ana nos indaga com seus atos se de fato podemos estabelecer uma linha divisória clara entre um acting out e uma passagem ao ato, ou se em um momento sutil e inapreensível, o sujeito que está ali, na cena do Outro, caísse.

\section{Passagem ao Ato e Estruturas Clínicas}

Procurando estabelecer uma diferença entre a passagem ao ato na neurose e na psicose, Carvalho (2002, p. 68) esclarece que "a passagem ao ato na neurose é justamente a precipitação do sujeito, a partir de um encontro desestabilizador, para fora da cena fantasmática onde ele ocupava uma posição de resposta ao desejo do Outro". Já na psicose, como gozo e Outro não se separam, há uma tendência "a operar diretamente sobre o real nos fenômenos de passagem ao ato, em suas tentativas de barrar o Outro em sua dimensão invasiva e excessiva" (p. 68).

$\mathrm{Na}$ clínica da neurose, a angústia é um guia e o manejo clínico vai em direção ao real a partir da mediação simbólica. Se o ato analítico visa extrair da angústia a sua certeza, a questão é como chegar até aí bordeando o campo da passagem ao ato e do acting-out com os quais a angústia faz fronteira. Por meio da pergunta "Que queres?", o neurótico interroga o desejo do Outro. Já na psicose, a angústia está a céu aberto e não funciona como um sinal. Ocorre aqui a impossibilidade formal de se fazer a pergunta pelo desejo do Outro. Ao contrário da neurose, onde o objeto $a$ é extraído do corpo negativizado pela castração, na psicose o sujeito encarna o objeto,

por conseguinte, falta a moldura que daria à angústia a sua contenção, falta a falta, como dirá Lacan, o contorno significante do objeto. Por isso o sujeito seria lançado mais facilmente ao ato enquanto a angústia tenderia a aparecer mais do lado do Outro. (Carvalho, 2002, p. 75)

Assim, o campo da passagem ao ato apresenta-se mais disperso na psicose, já que, por não ser limitado pela fantasia, o gozo aí predispõe o sujeito ao ato. Diferentemente da neurose, onde há um emolduramento da fantasia, na psicose há uma maior propensão à passagem ao ato.

O que foi se configurando a partir do acompanhamento de Ana evidenciava que os processos a que respondia judicialmente não tinham para ela o mesmo lugar que a própria equipe que acompanhava o caso no PAIPJ dava a eles. Suas questões passavam principalmente pelos filhos que desejava recuperar, pelas relações com a família, com os homens e pelo trabalho. Sempre se evidenciavam suas dificuldades em lidar com tais situações, comumente inseridas num contexto no qual agressões e brigas se apresentavam como sua forma de responder aos impasses que vivia, respostas sem sustentação de um discurso, sem subordinação da palavra.

Em novo atendimento, Ana espalha radiografias, além de muitas receitas e outros papéis dos processos sobre a mesa. Aponta para a radiografia da coluna vertebral e diz: "Essa é do braço" (sic). Era tão evidente se tratar de uma radiografia da coluna que, a princípio, supôs-se que era apenas um lapso de Ana, mas verificando com ela, constatamos que de fato para ela aquilo que se mostrava era um braço. Esse episódio revela um modo já anunciado de Ana relacionar-se com seu corpo desconhecido, corpo estranho, despedaçado. Essa relação parece dar pistas sobre as inúmeras atuações de Ana, nas quais ela se reduzia a um corpo "em crise", um corpo que se convulsionava, que se deixava cair, atropelar, quebrar, cortar, bater, ser batido.

A partir das inúmeras atuações de Ana, constrói-se que algo se repetia não no simbólico, mas no real; suas quebradeiras, que incluíam seu próprio corpo, pareciam indicar uma quebra do simbólico, algo que aí não operava, apontando para uma estrutura psicótica. Para Ana, o simbólico não estabelece medida eficaz. Ana se conjuga em corpo e ato.

Em determinado dia, recebemos um telefonema do companheiro de Ana. Ele então descreve uma cena ocorrida na sexta-feira à noite na qual Ana se mostrava agitada e agressiva, tanto com ele como em relação a si própria. Primeiramente, ela pegou uma faca que estava sobre a pia da cozinha e tentou cortá-lo, mas ele a conteve. 
Depois, bate reiteradamente na própria cabeça com uma panela. Em seguida, ingere seus medicamentos em grande quantidade. "Acho que ela queria tirar a vida dela", afirma o companheiro Emerson. Depois de um tempo, Ana começa a respirar muito forte, quando então Emerson aciona o Serviço de Atendimento Móvel de Urgência (SAMU).

O que se revela nessa cena descrita por Emerson são pontos que parecem ir embaraçando, um embaraço que, num crescente de agitação e movimento, culmina em sua passagem ao ato como uma solução radical para pôr fim à angústia que a invade. Vale destacar nessa cena como Ana ao ser contida por Emerson, passa a golpear a si mesma, o que se apresenta como uma confusão imaginária, ou seja, o que é seu corpo e o que é corpo do outro.

Em seu seminário sobre os escritos técnicos de Freud, Lacan (2009) faz menção a um esquema da física ótica chamado de "experimento do buquê invertido", no qual um espelho esférico produz uma imagem real ali onde não há um objeto na realidade. Partindo desse esquema, Lacan demonstra como a relação do mundo imaginário com o mundo real estrutura a vida psíquica de cada sujeito. Esse autor propõe ainda que se o processo de maturação fisiológica permite ao sujeito integrar efetivamente suas funções motoras, e aceder a um domínio real do seu corpo, é, todavia, num momento que antecede o momento de maturação que o sujeito toma consciência de seu corpo como totalidade. A vista da forma total do corpo humano no espelho dá ao sujeito um domínio imaginário do seu corpo, mesmo que prematuro em relação ao domínio real, ou seja, dirá Lacan, “(...) a imagem do corpo, se a situamos no nosso esquema, é como o vaso imaginário que contém o buquê de flores real" (Lacan, 2009, p. 109). É em seu texto "O estádio do espelho como formador da função do eu" que Lacan (1998) propõe que o sujeito antecipa-se ao acabamento do domínio psicológico, e essa antecipação dará seu estilo a todo exercício posterior do domínio motor efetivo, donde a imagem do corpo dá ao sujeito a primeira forma que lhe permite situar o que é e o que não é do eu. Essa digressão nos permite pensar que no caso de Ana, frente a um eu não unificado, um corpo despedaçado que não sofre subordinação da palavra, suas passagens ao ato se apresentam como a única reposta (motora) que ela encontra para lidar com o mal-estar que a invade.

Ana permaneceu mais de um mês no Centro de Terapia Intensiva do Pronto Socorro. Foi necessária a realização e uma traqueostomia devido à gravidade da pneumonia adquirida. Em conversa realizada com a equipe médica, esta informa que Ana se agitava muito, arrancava os acessos venosos, puxava a traqueostomia, razão que levou a equipe a ter que mantê-la sedada, situação que, segundo pontuou o médico, diminuía a possibilidade de ela reagir contra a pneumonia, mas não se verificava outra solução. Em uma das visitas à paciente, suas mãos estavam amarradas à cama.

Com o decorrer dos dias, a pneumonia cedeu e Ana retornou para casa de Helena. O serviço de saúde passou a tratá-la. Com a retomada do acompanhamento pelo PAIPJ, Ana parecia melhor, apesar de muito magra. Contudo, voltou a fumar e, em pouco tempo, acabou pegando outra pneumonia, quando foi necessário fazer outra traqueostomia. Todavia, a equipe médica permitiu que ela fosse para casa, quando ela retornou para o barracão com Emerson. Ana então arrancou o tubo que lhe permitia respirar. Da primeira vez ela foi socorrida pelo SAMU, a partir do pedido de socorro de Emerson; da segunda vez eles não chegaram a tempo. Ana veio a óbito.

\section{Sobre Ato e Angústia}

Pensar a angústia como signo do encontro com o real implica em conferir a ela o valor de um sinal, de aviso, último anteparo antes do abismo. Na neurose, observa-se que a angústia coloca o sujeito a certa distância da experiência do real, introduzindo desse modo um intervalo entre o sujeito e o gozo mortífero, um intervalo que possibilitaria algum manejo subjetivo, sem desaparição da sua condição de sujeito. Todavia, essa função da angústia na neurose, que se refere a uma inserção no funcionamento significante, pode não ocorrer na psicose, já que nesta a angústia aparece, muitas vezes, concomitantemente à emergência do real ${ }^{3}$.

A hipótese em relação ao caso de Ana é que nem todos os sujeitos psicóticos podem se utilizar da função da angústia enquanto sinal, e a diferença principal está em "tocar" o real, "vislumbrar" algo do real que se utiliza para os neuróticos, e o "introduzir-se" no real do psicótico; a diferença entre olhar de perto e estar no abismo.

Ana se mostra em permanente queda no abismo, o que se evidencia pelas inúmeras lesões que apresenta ao ser atropelada, cair, agredir, ser agredida. Parece não haver nenhum intervalo entre isso que lhe provoca o Outro em uma dimensão invasiva, excessiva e seu "ato-resposta": "Vou arrasar com tudo" (sic). Seus atos seguem um continuum que invoca, como aponta Miller (2005, p. 78), o movimento de um carretel, um ir e vir que vai de actings out a passagens ao ato, sem que conseguíssemos lhe ofertar um anteparo, algo que conectasse Ana ao Outro. As questões que envolvem seu processo judicial de nada lhe servem como borda para corpo, ela não consente em recordar e age.

Ao longo do acompanhamento, o que se verifica é que Ana não faz suposição de saber. A falta de tal suposição e da simbolização que seria propiciada pela inscrição do

3 Para uma leitura sobre o tema conferir: Prota, F. G. (s/d) Recuperado em 16 de outubro de 2011, de http://ebp.org.br/wp-content/ uploads/2012/08/Fernando_Del_Guerra_Prota_Uma_funcao_para_a_ angustia_na_psicose1.pdf 
significante do Nome-do-Pai no Outro põe em evidência a fragilidade das amarras simbólicas e de seu corpo. O que Ana nos mostra é a impossibilidade de apropriar-se de um corpo e de percebê-lo como formando uma unificação. Seu corpo desenlaçado se convulsiona sem que haja alguma possibilidade de enlaçamento, seja no tratamento na rede de saúde mental, seja no acompanhamento do PAIPJ. O que ela quer são coisas que lhe permitam se assegurar de ter um corpo: um vestido, os filhos, a possibilidade de engravidar novamente.

Entretanto, ao mesmo tempo em que ela evidencia uma relação estrangeira com o próprio corpo, como se ele fosse um outro, um objeto estranho, uma alteridade que não lhe faz questão, em momentos que podemos chamar de crise, sua relação se apresenta de forma distinta: parece não haver nenhum tipo de barreira ou censura, nenhum amortecimento ou recurso para lidar para o mal-estar que lhe toca o corpo. O corpo como alteridade a esmaga e domina, um insuportável que aniquila sua possibilidade de seguir enquanto um sujeito.

Nossa hipótese é a de que Ana é invadida por um inominável, um gozo à deriva, que não se localiza e diante do qual ela não tem recurso: marcado por um tubo enfiado em seu pescoço, condição para que ela respire e continue viva. Todavia, não nos parece que quando retira a cânula que lhe permitia respirar, houvesse para ela a intenção de morrer, mas sim a evidência de sua impossibilidade em lidar com o insuportável da invasão da parafernália médica em seu corpo e da angústia que isso lhe provocava. Assim Ana atravessa a linha sutil que separa a vida da morte, um tubo que a atravessa.

\section{Considerações Finais}

Foi-nos possível elucidar que se a passagem ao ato mantém a mesma estrutura, seja na neurose ou na psicose, na primeira, a passagem ao ato é a precipitação do sujeito, a partir de um encontro desestabilizador, para fora da cena da fantasia. Já na psicose, na tentativa de barrar o Outro que surge em uma dimensão invasiva, haveria uma tendência a operar diretamente sobre o real via passagem ao ato. Assim, o campo da passagem ao ato apresenta-se mais disperso na psicose, já que, por não ser limitado pela fantasia, o gozo aí predispõe o sujeito ao ato.

Ana nos traz indagações sobre pontos teóricos importantes, como o fato de que suas atuações pareciam estabelecer certa opacidade entre o que era ordem de um acting out e o que era da ordem de uma passagem ao ato, como se, em um momento inapreensível, e muito rápido, o sujeito que estava ali, na cena do Outro, escorregasse, sumisse, caísse, sem que conseguíssemos lhe estender a mão.
Assim, Ana questiona alguns pressupostos teóricos: até onde podemos ter clareza dessa linha, muitas vezes tênue, que separa uma passagem ao ato de um acting out? Como localizar e intervir a partir dos pontos de angústia que muitas vezes antecedem o ato - um anúncio, por exemplo, mas que no caso de Ana pareciam estar "curto-circuitado", ou seja, angústia a céu aberto, não funcionando como um sinal que possibilitasse uma intervenção antes do ato.

E a morte? Ato sem palavra: a morte, esse impossível de dizer. A morte que pode ou não ser evitada? Enfim, a insuficiência da teoria, do simbólico para dar conta do real, com o real do caso: a morte de Ana.

Mas a escrita fica como uma passagem, neste caso, falha, malsucedida; a passagem de um texto, pois como aponta Machado (2008), a psicanálise se afasta radicalmente das pretensões universitárias - tanto no sentido da universalização quanto da instituição -, especialmente a de impor um modo de enunciar a gramática do real. Em vez disso, cabe a cada um inventar um escrito a partir do incurável de seu sintoma.

\section{Referências}

Carvalho, F. F. (2002). Psicose e passagem ao ato. Abrecampos - Revista de Saúde Mental do Instituto Raul Soares, 2(2), 66-79.

Freud, S. (1996a). Fragmento da análise de um caso de histeria. In J. Strachey (Ed.), Edição Standard Brasileira das Obras Completas de Sigmund Freud (Vol. 7). Rio de Janeiro: Imago. (Originalmente publicado em 1905)

Freud, S. (1996b). Recordar, repetir e elaborar. In J. Strachey (Ed.), Edição Standard Brasileira das Obras Completas de Sigmund Freud (Vol. 12). Rio de Janeiro: Imago. (Originalmente publicado em 1914)

Freud, S. (1996c). A psicogênese de um caso de homossexualismo numa mulher. In J. Strachey (Ed.), Edição Standard Brasileira das Obras Completas de Sigmund Freud (Vol. 18). Rio de Janeiro: Imago. (Originalmente publicado em 1920)

Lacan, J (1998). O estádio do espelho como formador do eu. In Escritos (pp. 96-103). Rio de Janeiro: Jorge Zahar.

Lacan, J. (2009). O Seminário Livro 1: Os escritos técnicos de Freud. Seminário de 1953-54. Rio de Janeiro: Jorge Zahar.

Lacan, J. (2002). O Seminário Livro 3: As psicoses. Seminário de 1955-56. Rio de Janeiro: Jorge Zahar.

Lacan, J. (2005). O Seminário Livro 10: A angústia. Seminário de 1962-63. Rio de Janeiro: Jorge Zahar. 
Machado, J. P. (2008). Psicanálise e universidade: mais, ainda. In A. C. Lo Bianco (Org.), Freud não explica: A psicanálise nas universidades (pp. 29-38). Rio de Janeiro: Contra Capa.

Miller, J.-A. (2005). Introdução à leitura do seminário de Angústia de Jacques Lacan. In Opção Lacaniana, 43, (pp. 7-91), São Paulo.

Tribunal de Justiça de Minas Gerais. Programa de Atenção Integral ao Paciente Judiciário Portador de Sofrimento Mental (PAI-PJ). Recuperado em 16 de outubro de 2011 em: http://www.tjmg.jus.br/portal/acoes-e-programas/ novos-rumos/pai-pj.
Endereço para correspondência:

Gabriela Rodrigues Mansur de Castro

Endereço: Rua Nepomuceno, no 415/302, Prado.

Belo Horizonte/MG. - CEP: 30.411-156

E-mail: gabrielamansur@yahoo.com.br

\section{Endereço para correspondência:}

Ângela Maria Resende Vorcaro

Endereço: Rua Paul Bouthilier, no 353, Mangabeiras.

Belo Horizonte/MG. - CEP: 30315-010

E-mail: angelavorcaro@uol.com.br 